\title{
Contribuições à Prática do Psicólogo na Educação Profissional
}

Contributions to the Psychologist's Practice in Vocational Education

Contribuciones a la Práctica del Psicólogo en la Educación Profesional

Juliana Prediger \& Rosane Azevedo Neves da Silva

Universidade Federal do Rio Grande do Sul

http://dx.doi.org/10.1590/1982 - 370001082012
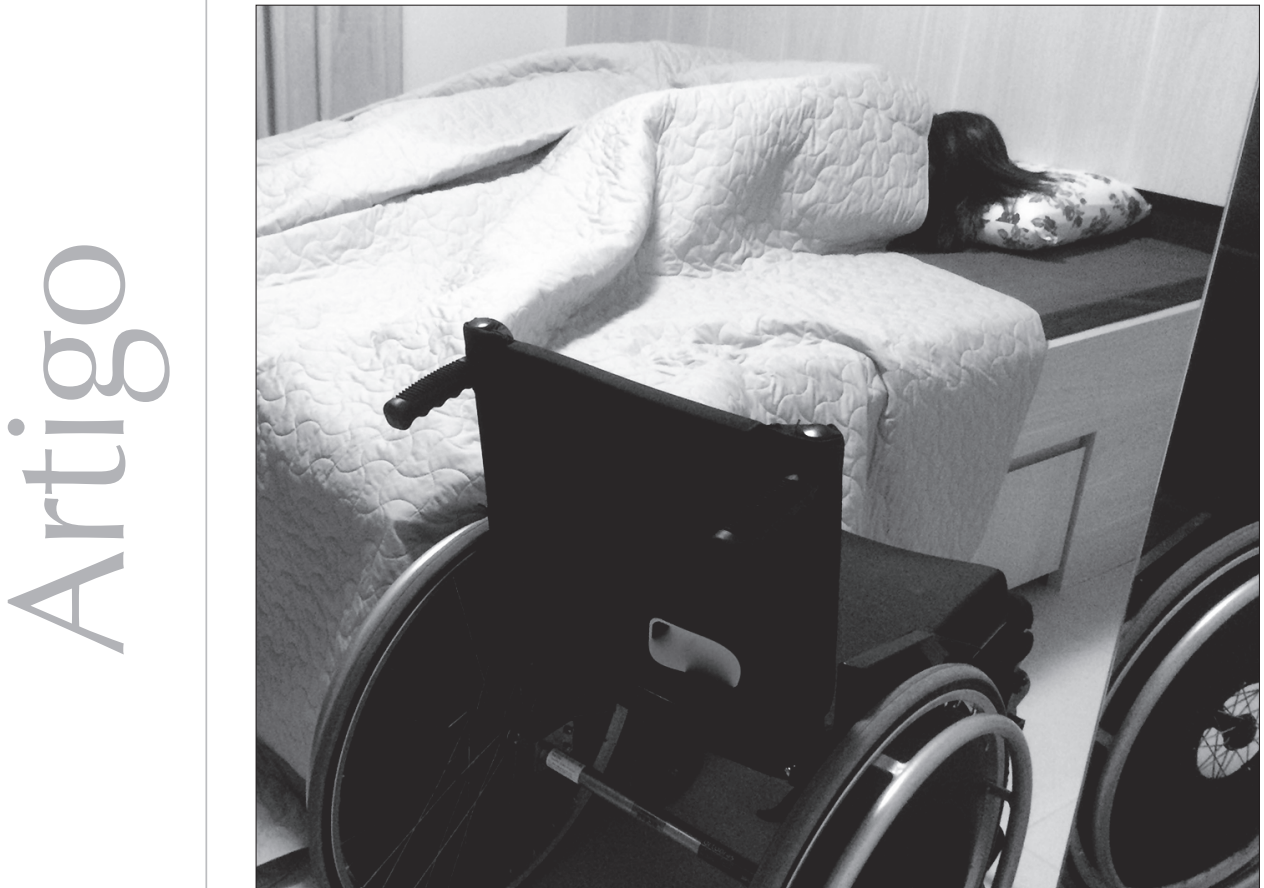
Resumo: Houve recentemente no Brasil um massivo incremento da educação profissional, científica e tecnológica, especialmente representada pelos Institutos Federais. Esse incremento foi marcado pela expansão da rede por meio da criação de centenas de novas unidades e contratação de milhares de profissionais. As novas contratações trouxeram um grande número de psicólogos e psicólogas para atuar na Educação Profissional. Este trabalho narra a experiência da criação de um espaço de diálogo entre os psicólogos inseridos nos Institutos Federais. Tal experiência, uma pesquisa-intervenção, teceu uma rede entre esses psicólogos por meio de um fórum virtual, que se tornou um espaço permanente para compartilhamento de experiências.

Palavras-chave: Psicologia Escolar. Educação. Ensino profissionalizante. Atuação do psicólogo.

Abstract: Recently, there has been a massive increment of Vocational education and training in Brazil, both scientific and technological, particularly represented by Federal Institutes. This increment was marked by the expansion of network through the establishment of hundreds of new units and hiring of thousands of professionals. This new hiring brought in a large number of psychologists to work in vocational education. This paper narrates the experience of creating a dialogue space among psychologists inserted in the Federal Institutes. Such experience, an intervention survey, weaved a net among those psychologists via a virtual forum that became a permanent space for sharing experiences.

Keywords: School psychology. Education. Vocational education and training. Psychologist performance.

Resumen: Hubo recientemente en el Brasil un masivo incremento de la Educación profesional, científica y tecnológica, especialmente representada por los Institutos Federales. Este incremento fue marcado por la expansión de la red a través de la creación de centenas de nuevas unidades y contratación de millares de profesionales. Estas nuevas contrataciones han traído un gran número de psicólogos y psicólogas para actuar en la educación profesional. Este trabajo narra la experiencia de la creación de un espacio de diálogo entre los psicólogos inseridos en los Institutos Federales. Tal experiencia, una pesquisa-intervención, ha tejido una red entre estos psicólogos a través de un fórum virtual, que se ha tornado un espacio permanente para compartimiento de experiencias.

Palabra-clave: Psicología escolar. Educación. Enseñanza de formación profesional. Actuación del psicólogo. 
No ano de 2008, é sancionada a lei de criação dos Institutos Federais de Educação, Ciência e Tecnologia. Formados pela união dos Centros Federais de Educação Tecnológica (CEFETs), das escolas agrotécnicas, das escolas técnicas ligadas às universidades federais e por centenas de novas unidades, os Institutos Federais passam a ser os principais responsáveis por implementar as políticas de educação profissional e tecnológica especialmente aos públicos que historicamente estiveram excluídos dos processos educativos. Ao mesmo tempo em que a rede é remodelada e transformada, ela é expandida com a criação de centenas de novos campi por todo o Brasil com o objetivo de descentralizar e regionalizar a educação profissional. Essa expansão também se deu por meio do incremento do quadro de pessoal e a figura do profissional da Psicologia passou a ser parte deste cenário.

É nesse contexto que uma das autoras deste relato ingressa em um Instituto Federal, em um campus situado a $500 \mathrm{~km}$ da capital do estado. Essa entrada é marcada inicialmente pelo estranhamento com as demandas à Psicologia e pelo isolamento, por uma solidão profissional.

As questões apresentadas pela instituição ao psicólogo criam um impasse entre atender às tradicionais demandas endereçadas à Psicologia na escola ou problematizar tais demandas, tomando-as como analisadores a fim de potencializar novas práticas possíveis para a Psicologia no contexto da educação.

Ao assumirmos a postura de problematização da demanda, a questão da solidão tornou-se mais impactante: não havia articulação alguma entre os psicólogos da rede, nem análises coletivas das práticas desenvolvidas por esses profissionais. A situação que estava dada era a de dispersão em função das distâncias entre os municípios que sediam os campi dos Institutos Federais em todo o país.

Foi essa situação inicial de dispersão que alavancou a criação de um território comum, um território de encontro, onde os diversos profissionais da Psicologia poderiam compartilhar suas experiências e angústias relacionadas à atuação profissional.

Este trabalho é relato da experiência de uma pesquisa-intervenção que concretizou o objetivo de constituir o referido território comum, o que se deu por meio da criação e consolidação de um fórum virtual enquanto espaço de diálogo entre os psicólogos da Rede Federal de Educação Profissional.

\section{Revisitando a Psicologia Escolar}

Ao longo de sua história, a Psicologia construiu saberes acerca da aprendizagem e legitimou um discurso sobre o aluno. Isso contribuiu para a construção de um lugar de patologização dentro do ambiente escolar e, por muito tempo, a Psicologia permaneceu distante de discussões acerca da dissociação feita pela escola entre ensinar e aprender. Lazzarotto (2003) observa que "O que deveria designar o fracasso das formas de ensinar constituídas pela estrutura da organização-escola, muitas vezes acaba por se visibilizar de forma individualizada como um problema de aprendizagem" (p. 227).

A demanda colocada pelas instituições escolares, diante das dificuldades que surgiram para os processos de aprendizagem, combinadas a uma determinada perspectiva clínica que acompanhava a prática da Psicologia, esteve presente na construção de uma Psicologia Escolar voltada para a patologização de dificuldades de aprendizagem e comportamento. Desse modo, acaba-se por privilegiar um enfoque clínico e individualizante para essa atuação. No entendimento de Martins, 
Sob a perspectiva da "psicologia escolar clínica", o trabalho do psicólogo tem como papel evitar desajustes ou desadaptações do aluno. Estes, por sua vez, são equacionados em termos de saúde $x$ doença, o que, na escola, é retraduzido como problemas de ajustamento e adaptação. A escola, como instituição, é tomada como adequada, cumpridora dos objetivos ideais que foram propostos. $(2003$, p. 40$)$

A partir da década de 80, são assumidas novas posturas e compromissos da Psicologia com a educação, de modo a romper com a antiga tradição adaptacionista. Martinez (2009) afirma ser compromisso central para os psicólogos que trabalham em contextos educativos "a transformação dos processos educativos, com a efetivação das mudanças necessárias que demanda a melhoria da qualidade da educação no país" (p. 169, grifo da autora).

Essas rupturas, iniciadas na década de 80 , continuam ocorrendo e as questões que naquele momento mobilizaram a Psicologia Escolar continuam atuais. Exemplo disso é a obra A produção do fracasso escolar, de Maria Helena Souza Patto. A referida obra tornou-se um clássico, referência para psicólogos, gestores e professores, apontandonos para a constatação de que as questões abertas pela democratização do acesso à escola, tais como o fracasso escolar de crianças de classes populares, continuam atuais (Carvalho, 2011).

Atualmente, o psicólogo encontra-se na delicada situação de ter de inventar outros modos de atuar na escola, colocando em questão as demandas individualizantes marcadas por perspectivas baseadas na adaptação e no ajustamento, tão fortemente enraizadas no papel atribuído ao psicólogo escolar. De acordo com Fernandes,
Romper com esse processo [individualizante, patologizante, excludente] é um caminho que requer a afirmação de outros compromissos e deve estar marcado por uma luta pela transformação social e contra a injustiça. É necessário desconstruir os processos de produção de fracasso. É necessário desmontar práticas focalizando os mecanismos que se engendram no cotidiano escolar para, a partir de sua recusa, inventar novas alianças com outros saberes. (2006, p. 147)

Os Institutos Federais também surgem com uma proposta de transformação social. Em seu documento sobre as novas concepções e diretrizes da educação profissional, o Ministério da Educação coloca como principal função da nova configuração dos Institutos Federais

a intervenção na realidade, na perspectiva de um país soberano e inclusivo, tendo como núcleo para irradiação das ações o desenvolvimento local e regional. O papel que está previsto para os Institutos Federais é o de garantir a perenidade das ações que visem a incorporar, antes de tudo, setores sociais que, historicamente, foram alijados dos processos de desenvolvimento e modernização do Brasil, o que legitima e justifica a importância de sua natureza pública e afirma uma educação profissional e tecnológica como instrumento realmente vigoroso na construção e resgate da cidadania e da transformação social. (MEC, 2008, p. 22)

Sabemos, no entanto, que as instituições não são compostas apenas por suas normas, documentos ou concepções oficiais. O modo como os indivíduos se relacionam com essas normas também compõe a instituição. Lourau chama de analisadores aquilo que permite revelar a instituição, que traz à tona os elementos que a compõem (Lourau citado por Altoé, 2004). Este trabalho propõe-se a 
identificar alguns analisadores junto aos psicólogos que atuam nos Institutos Federais e levantar questões sobre esse espaço de atuação profissional.

\section{Conhecendo os psicólogos dos Institutos Federais}

Partimos de um rastreamento dos endereços eletrônicos dos psicólogos que atuam nos Institutos Federais. Os psicólogos contatados foram convidados a responder um questionário sobre sua atuação nos Institutos Federais. Esse questionário, composto por quinze questões, buscou informações sobre o tempo de atuação, formação inicial e qualificações, tempo de atuação no Instituto Federal (ou instituição que deu origem ao Instituto Federal), demandas para o psicólogo em sua chegada à instituição e demandas que marcavam seu cotidiano de trabalho na instituição. Além de ter o objetivo de levantar um perfil e posicionamentos desses psicólogos sobre sua atuação profissional, essa etapa foi pensada como um disparador para a etapa seguinte.

Participaram vinte psicólogos na primeira etapa. Profissionais de todas as regiões brasileiras responderam o questionário: Região Norte: 1 ; Região Centro-Oeste: 2; Região Nordeste: 7; Região Sudeste: 6; Região Sul: 4. Independentemente do tempo em que estavam formados, 16 atuavam há menos de três anos na Rede Federal. Havia, por exemplo, um psicólogo com 28 anos de profissão e que estava na Rede Federal há apenas dois anos.

A segunda etapa caracterizou-se pela criação de um Fórum Virtual, no qual os psicólogos envolvidos na pesquisa puderam criar um espaço de discussão sobre seu trabalho nos Institutos Federais espalhados pelo Brasil.

A partir do questionário realizado com os psicólogos dos IFs foram levantados dois eixos que tomaremos para análise. O primeiro parte da própria caracterização dos psicólogos que estão atuando nos Institutos, suas formações, experiências e a iniciação enquanto psicólogo escolar no Instituto Federal, o que nos auxilia a evidenciar que persiste uma crise na atuação do psicólogo em âmbito escolar demarcada pelas mudanças de paradigma nesta atuação, ainda que estas mudanças não sejam recentes. O segundo eixo inclui a análise das demandas e dificuldades que surgem na prática da psicologia nos Institutos Federais, que levam a múltiplas criações por parte dos psicólogos e apontam para alguns desafios.

Foi possível identificar as principais demandas e dificuldades que surgem na prática dos psicólogos nos Institutos Federais. A maioria dos psicólogos ingressou no Instituto Federal há menos de 3 anos, o que se deve especialmente à expansão da Rede Federal de Educação Profissional. Ao ingressarem na instituição, vivenciaram, assim, sua primeira experiência em Psicologia Escolar. A pergunta "O que fazer enquanto psicólogo escolar?" perpassou diversas falas e atualiza a problematização da psicologia escolar quanto à necessidade de se inventar novas práticas, novos modos de atuar dentro da escola. Surgem relatos das dificuldades frente às demandas de ajustamento que a escola colocava e do quanto persistia um modelo de patologização das questões escolares que se expressava pela expectativa de uma intervenção individualizada. Muitos psicólogos perceberam a necessidade de romper com os estereótipos ali presentes, propondo para a instituição novas possibilidades de intervenção. Criar novas demandas significa provocar rupturas no modo de olhar o contexto da instituição. É de modo lento, porém, que este processo parece ocorrer na maioria dos casos, demonstrando como são arraigados os estereótipos em relação ao trabalho do psicólogo, ignorando o caráter político das práticas pedagógicas afirmado por Rocha (1999). 
Reconhecer que a psicologia não mais poderia estar dentro da escola ocupando uma função de promotora de exclusão ou de afirmação que a aprendizagem é apenas de responsabilidade do aluno, coloca agora ao psicólogo um compromisso com a invenção de novas práticas, de novos modos de atuar dentro da escola. É interessante demarcar que os Institutos Federais também estão tendo o desafio de construir suas práticas, pois apesar de a educação profissional possuir uma história no país e muitas das unidades que hoje são campus dos IFs serem estabelecimentos centenários, é com outra configuração administrativa e com novos desafios de níveis de ensino e de público-alvo que os Institutos são delineados. Este novo formato traz inclusive um estranhamento diante da sua caracterização como uma "escola", por ser um espaço híbrido, onde convivem tanto os ensinos de nível médio e superior, quanto programas de formação inicial e continuada e de pós-graduação.

Alguns participantes da pesquisa manifestaram dificuldades frente às demandas de ajustamento que a escola tem colocado aos psicólogos a partir de um perfil esperado dos estudantes quanto ao que é considerado "adequado" ou "normal". Demandas como esta se sustentam a partir de um olhar bastante conservador da gestão e das equipes de trabalho, criando entraves para que o psicólogo possa produzir deslocamentos nesta demanda, como por exemplo, a reflexão sobre este perfil de estudante esperado pela escola. A dificuldade de lidar com tais demandas apareceu ao longo da pesquisa como necessidade de uma maior "definição da atuação" e de uma maior delimitação e clareza do que constitui a prática do psicólogo no campo da educação. Percebemos que ao ingressar na rede federal, a maioria dos psicólogos tinha pouca ou nenhuma experiência/formação específica para trabalhar no âmbito educacional. Assim, foi com poucos recursos teóricos e práticos que estes profissionais entraram para atuar em Psicologia Escolar. Ao ingressarem, diversas demandas colocadas enquanto urgências pela instituição, dificultavam a análise do que, de fato, estava sendo demandado a cada pedido.

As mudanças na perspectiva da atuação no ambiente escolar propiciaram um espaço aberto à criação. A percepção dos participantes da pesquisa é de que, ao iniciarem seu trabalho no Instituto, depararam-se com a demanda por práticas individualizantes de ajustamento ou exclusão. Persistia o modelo de patologização das questões escolares e isto se expressava através das expectativas da resolução destas questões exclusivamente por meio da intervenção clínica individual. Em geral esta demanda clínica é concebida como o único modo de intervenção possível do psicólogo, uma intervenção com um viés nitidamente adaptacionista. Para romper com esta perspectiva, Guzzo et al. (2010) nos apontam para a importância de se entender a realidade brasileira, a fim de que se possa resistir às práticas individualizantes e patologizantes do fracasso escolar.

De modo geral, pudemos constatar que a maioria dos profissionais concorda que foi a sua própria atuação que proporcionou mudanças no modo pelo qual a instituição passou a perceber as possibilidades de atuação do psicólogo escolar. Houve, assim, um movimento afirmativo da prática destes profissionais, no sentido de levar propostas de intervenção não esperadas, criar e mostrar diferentes possibilidades de atuação, e não apenas a recusa de demandas que julgaram não ser de sua competência. Para além da recusa do que a escola apresenta como demanda, o compartilhamento de experiências provocado pela pesquisa possibilitou não apenas a reflexão sobre o pedido que estava sendo feito pela instituição, mas também a torção na lógica onde esta demanda estava ancorada, abrindo espaço para o surgimento 
de novas perspectivas de atuação. No decorrer da pesquisa, percebeu-se que o modo de posicionar-se frente às demandas da instituição proporcionou algumas modificações na expectativa estereotipada com relação ao trabalho do psicólogo. Estas modificações foram mais significativas entre os psicólogos que estavam há mais tempo na instituição, o que já não ocorreu com aqueles profissionais que ingressaram mais recentemente.

A questão aqui colocada nos leva a retomar o que tradicionalmente se configurou como atividade do psicólogo a partir de concepções balizadas pelo ajustamento que sustentavam esta atuação. É preciso manter permanentemente o questionamento iniciado na década de 80 que, segundo Proença (2008), consistia em interrogar a serviço de que e de quem estaria a Psicologia e a Psicologia Escolar.

Retornando à questão da demanda clínica evocada por parte da escola, é importante ressaltar que esta, tal como é colocada, refere-se ao atendimento individualizado e traz em si um pedido de ajustamento deste aluno. Mas surge entre os psicólogos o questionamento de como a clínica poderia estar colocada neste espaço de saber, educacional e institucional?

A abordagem individualizada é frequentemente questionada pelos psicólogos, sendo apontada como um dos problemas com o qual precisam lidar no contexto escolar. É insistentemente lembrada pelos participantes da pesquisa a expectativa, por parte da instituição, pela intervenção clínica individual. Visualizamos que esta demanda que surge sob o nome "clínica" é uma demanda por ajustamento. No entanto, a superação de uma "abordagem individualizada e individualizante" é mencionada como experimentação e desafio. Durante o fórum virtual de discussões, a clínica passou a ser problematizada como um dispositivo, uma potência e não apenas em seu aspecto individualizante.
A "demonização" dos "atendimentos individuais" coloca-nos numa lógica de pensamento de que o individual é uma oposição ao institucional. Cabe frisar que a clínica não precisa estar a serviço da corroboração das visões patologizantes sobre o aluno, não havendo contradição entre a clínica e o trabaIho de questionamento e desnaturalização dos problemas que a escola tem colocado à Psicologia. Reafirma-se, assim, o que dizem Passos e Barros: "Queremos afirmar que toda propriedade de si guarda um fundo de impropriedade, de impessoalidade que faz da experiência clínica uma prática nunca completamente privada ou particular, mas pública, isto é, atravessada pela polis, pela política" (2009, p. 162). Aponta-se, assim, para um desvio de uma clínica de ajustamento, sublinhando uma clínica da vida, uma clínica de potencialização da vida, "um modo de clinicar e de viver que expresse a potência e o desejo, deixando, dessa maneira, a vida exceder-se" (ROMAGNOLI, 2006, p. 54).

Temos, assim, a possibilidade de atender as questões da escola, transformando esta demanda. Trata-se de um campo por inventar, onde se possam acolher diferentes experimentações. A partir da dificuldade em lidar com as expectativas dominantes em relação ao trabalho do psicólogo, surge, algumas vezes, a ânsia por definições que circunscrevam a atuação profissional. Este estudo procurou mostrar novos contornos dos quereres dos psicólogos em sua atuação.

\section{CONSIDERAÇÕES FINAIS}

A necessidade de dialogar foi o passo inicial que moveu este trabalho e desde o primeiro contato com cada psicólogo algo estava se produzindo, algo estava sendo mobilizado. O Fórum Virtual trouxe a possibilidade de uma rede de conversação dos psicólogos da educação profissional. Ele permitiu levantar questões, pensar os lugares que usamos, que 
criamos, que abandonamos ou que redesenhamos. Ao olharmos para o processo desta pesquisa, é possível acompanhar a criação de determinados territórios e a desestabilização de outros.

Para conhecermos as práticas que os psicólogos estão construindo nos IFs foi necessário criar um espaço de discussão. Naquele momento, o espaço possível foi o fórum virtual e este espaço provocou algumas transformações nas práticas dos próprios psicólogos que proporcionaram a criação de novos territórios, que abrigaram novos desejos.

Um importante efeito desta intervenção foi o rompimento com o lugar de solidão dos psicólogos e a criação de possibilidades de interlocução. O fórum virtual, mesmo encerrada a pesquisa, continuou ativo, sendo que atualmente conta com quase 200 membros. Neste espaço, ainda ocorrem discussões, sendo possível analisar coletivamente as questões que se colocam à prática da psicologia nas instituições de educação.

Tendo como ponto de partida o isolamento profissional, que mobilizou esta pesquisa, houve a criação de um espaço de encontro e debate. Partiu-se do individual para uma experiência política, abrindo-se para uma sensibilidade dos atravessamentos políticos em nossas práticas. O trabalho disparou a discussão e a reflexão sobre diversos temas referentes ao contexto da educação e, especialmente, às peculiaridades vividas nos Institutos Federais, mostrando que é possível encontrar novas produções de sentido para as práticas do psicólogo no âmbito da escola.

O Fórum Virtual constituiu-se, assim, em um dispositivo clínico-político que possibilitou levantar questões, pensar os lugares tradicionais da psicologia escolar e criar novas estratégias de intervenção.

O principal efeito desta intervenção foi romper com o lugar de solidão dos psicólogos. A pesquisa foi um disparador desse movimento, convidando à discussão, trazendo alguns temas ao debate, criando um ambiente virtual para facilitar estas trocas, embora nada disso se sustentasse se não houvesse ali, entre os psicólogos participantes, um desejo de que acontecessem estas conversas, um desejo de que bons encontros pudessem produzir novas experimentações e outros sentidos para a psicologia escolar.

\section{Juliana Prediger}

Mestre em Psicologia Social e Institucional pela Universidade Federal do Rio Grande do Sul, Porto Alegre - RS. Brasil.

E-mail: jprediger@gmail

\section{Rosane Azevedo Neves da Silva}

Doutora em Educação pela Universidade Federal do Rio Grande do Sul, Porto Alegre- RS. Brasil.

Docente da Universidade Federal do Rio Grande do Sul, Porto Alegre- RS. Brasil.

E-mail:00076369@ufrgs.br

\section{Endereço para envio de correspondência:}

Rua Coronel Vicente, 281, Centro Histórico. CEP 90030-041, Porto Alegre - RS

Recebido 14/05/2013, 1ㅍ- Reformulação 18/05/2013, Aprovado 16/10/2013. 
Altoé, S. (Org). (2004).René Lourau: Analista Institucional em Tempo Integral. São Paulo: HUCITEC.

Brasil. (2008). Lei n. 11.892, de 29 de dezembro de 2008. Institui a Rede Federal de Educação Profissional, Científica e Tecnológica, cria os Institutos Federais de Educação, Ciência e Tecnologia, e dá outras providências. Diário Oficial [da] República Federativa do Brasil, Brasília, DF, Seção 1, p. 4.

Carvalho, J. S. F. de. (2011). A produção do fracasso escolar: a trajetória de um clássico. Psicologia USP, 22(3), 569-578. doi: 10.1590/S0103-65642011005000023.

Fernandes, Â. M. D. (2006). Histórias e práticas do sofrer na escola: múltiplos atos/atores na produção do "aluno-problema". In A. M. Machado, Â. M. D. Fernandes, M. Lopes (Orgs.), Novos possíveis no encontro da psicologia com a educação. (Cap 7, pp. 145166). São Paulo: Casa do Psicólogo.

Lazzarotto, G. D. R. Trabalhar para educar, educar para trabalhar: compondo outros lugares de diálogo entre educação e trabalho. In C.
Maraschin, L. B. L. Freitas, \& D. C. de Carvalho. (Org.), Psicologia e Educação: Multiversos sentidos, olhares e experiências. Porto Alegre: Editora da UFRGS.

Martins, J. B.(2003). A atuação do psicólogo escolar: multirreferencialidade, implicação e escuta clínica. Psicologia em Estudo, Maringá, $8(2)$, 39-45. doi: 10.1590/S141373722003000200005

Martinez, A. M. (2009). Psicologia Escolar e Educacional: compromissos com a educação brasileira. Psicologia Escolar e Educacional, 13(1), 168-178. doi: 10.1590/S141385572009000100020

Rocha, M. L., Ramos, A. C., Breia, V. C., \& Pimenta, T. de J. (1999). O psicólogo na escola: história e formação. Clio-Psyché, Rio de Janeiro, 1, 215-224.

Romagnoli, R. C.(2006, jul.-dez.) Algumas reflexões acerca da clínica social. Revista do Departamento de Psicologia - UFF, 18(2), 47-56. doi: 10.1590/S010480232006000200004 . 